\title{
Sobre los límites de la estemática maasiana: Los Hechos Apócrifos de Tomás y su lengua original
}

\author{
ISRAEl MuÑoz GaLlarTe \\ Universidad de Córdoba
}

Título: Sobre los límites de la estemática maasiana: Los Hechos Apócrifos de Tomás y su lengua original.

Resumen: La presente nota filológica pone de manifiesto los límites a los que se enfrenta la estemática maasiana al abordar la edición de textos marcados por el sello de los orígenes del Cristianismo. Para ejemplificar el problema, se aborda una de las cuestiones filológicas más debatidas en la literatura académica actual, como es la de la lengua originaria en que fueron escritos los $\mathrm{He}$ chos apócrifos de Tomás (HT).

Palabras clave: Paul Maas, Crítica textual, Contaminatio, Hechos apócrifos de Tomás.

Fecha de recepción: 11/12/2016.

Fecha de aceptación: 29/12/2016.
Title: Regarding the Mass's Esthematic: The Apocryphal Acts of Thomas and its Original Language.

Abstract: The present philological note deals with the borders of the Paul Maas's theory when it is applied to the texts labelled under the title of the Origins of Christianism. To do so, the following pages bring to a light on one of the most debated topics in the current academia, such as that regarding the original language of the socalled Apocryphal Acts of Thomas.

Key words: Paul Maas, Textual Criticism, Contaminatio, Apocryphal Acts of Thomas.

Date of Receipt: 11/12/2016.

Date of Approval: 29/12/2016. 
En aquel Imperio, el Arte de la Cartografía logró tal Perfección que el Mapa de una sola Provincia ocupaba toda una Ciudad, y el Mapa del Imperio, toda una Provincia.

Jorge Luis Borges, "Del rigor en la ciencia", en El hacedor, Madrid, 2003, p. 76.

\section{INTRODUCCIÓN}

La búsqueda de una exactitud absoluta no es sólo un imperativo categórico de las Ciencias. A pesar de las dificultades intrínsecas que impone el tratar materias tan resbaladizas y traicioneras como las humanas, no nos faltan empeños que aspiran a conseguir resultados casi matemáticos. La crítica textual de corte lachmanniano codicia —en su formulación de la estemática de Paul Maas - ser una herramienta para obtener resultados incontrovertibles, pero, sin duda, se enfrenta a dificultades, como la contaminatio.

Intentemos repasar, siquiera someramente, las bases sobre las que se asienta el fenómeno de la contaminación, según la descripción de su autor y su recepción en la crítica textual de hoy.

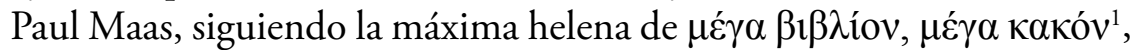
se muestra realmente conciso al definir el fenómeno y califica el ejemplar contaminado mediante dos condiciones esenciales: a) el manuscrito "no muestra errores particulares del ejemplar del cual ha derivado"; b) "muestra errores propios de aquellos ejemplares de los que esencialmente no depende" ${ }^{2}$. A su vez, las raíces de este problema Maas las sitúa en el hecho de que en un manuscrito $F$ :

... se anotan al margen o entre líneas lecciones divergentes de otro (digamos $A$ ) que no es el ejemplar de $F$; $J$ después sigue otra la lección primaria, ora la lección secundaria de $F$. Si después $A$ y $F$ se han perdido, entonces las relaciones de dependencia de $J$ ya no resultan claras, porque $J$ en tal caso mostrará tanto errores particulares de $\delta$ (pero no todos los errores de $\delta$ ), cuanto errores particulares de $\beta$ (pero

1 Paul Maas, Crítica del Texto, trads. Andrea Baldissera y Rafael Bonilla Cerezo, Sevilla, Universidad Internacional de Andalucía, 2012, p. 11.

2 Trad. de Andrea Baldissera y Rafael Bonilla Cerezo, op. cit., pp. 35-36. Para una descripción del stemma, según estas condiciones, véanse pp. 31 y 36. 
no todos los errores de $\beta$ ).

El diagnóstico y las causas de la enfermedad, por tanto, parecen claros, como también los posibles pacientes, los que directamente nos conciernen, los textos griegos apócrifos englobados en la abigarrada tradición de los Hechos Apócrifos de los Apóstoles 3 . Para ellos Maas advierte que "en presencia de una contaminación mengua el rigor de la estemática" "y que, desafortunadamente, "contra la contaminación no se ha descubierto ningún remedio"5.

Alberto Blecua, en su precioso Manual de critica textual $^{6}$, a pesar de que tampoco encuentra un antídoto contra la contaminación, clarifica, a partir del modelo, su definición ${ }^{7}$ :

La contaminación se detecta cuando dos o más testimonios presentan errores conjuntivos y a su vez uno de ellos da una lección que coincide no accidentalmente con la de otra rama, que previamente ha sido separada de la anterior por los errores separativos.

Precisa el investigador, además, la necesidad de no confundir entre los errores producidos por contaminación con los "errores evidentes", con las "correcciones conjeturales" del copista ni, especialmente, con "cambios y modernizaciones", producto de que la copia se realice en un contexto cultural distinto respecto del original ${ }^{8}$.

Finalmente, con el interés de volver al campo exclusivo de las clásicas y por su fundamentada crítica de la estemática maasiana, merece la pena

3 Sobre cómo la contaminatio afecta especialmente a los textos clásicos que proceden de tradición medieval, véase Alberto Blecua, Manual de crítica textual, Madrid, Castalia, 2001, pp. 91 y 94. Acerca del caso concreto de los mss. griegos de HT, véanse las conclusiones de M. Bonnet, Acta Thomae. Supplementum Codicis Apocryphi, 1 (Leipzig, 1883) XXII: "non est eadem ratio librorum $P R$, nam $R$ ita inter $P$ et $Q G$ nutat et fluctuat ut ex utraque familia contaminatus videatur".

4 Paul Maas, op. cit., p. 78.

5 Paul Maas, ibidem, p. 79, n. 58.

6 Alberto Blecua, op. cit., pp. 91-94; ejemplo en pp. 95-101.

7 Alberto Blecua, ibidem, p. 91 y n. 1. Sobre este problema y el intento de Pasquali de dar una solución al problema, véase Alberto Bernabé, Manual de crítica textual y edición de textos griegos, Madrid, Akal, 2010, p. 54, n. 15.

8 Alberto Blecua, op. cit., p. 91 y n. 1. 
traer a colación el Manual de crítica textual y edición de textos griegos de Alberto Bernabé. En efecto, el investigador describe brevemente el modelo de Maas basado en la diferenciación entre errores conjuntivos y separativos, tras lo que incluye esta paradoja:

Considerando, como suele hacerse tradicionalmente, que el verso (scil. S., OT 800) es auténtico y no un ańadido posterior, resultaría que son precisamente los manuscritos más recientes (recentiores) los que han preservado la lectura correcta, frente al antiquior Laurenciano, algo que iría contra su célebre máxima de recentiores deteriores. Además, bajo esta misma premisa, también resultaría que los manuscritos que lo transmitiesen estarían emparentados, de modo que no sólo la coincidencia en el error (la omisión) sería significativa; también la coincidencia en el acierto?.

Además, como conclusión, Bernabé apunta que en el método, una vez establecida la relación entre los manuscritos, "cuando se llega a un testimonio frente a uno, la selección automática no es posible y hay que recurrir a la examinatio y a la selectio, de forma que en este punto, la llamada

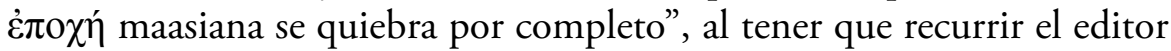
a elementos subjetivos, más que a los objetivos ${ }^{10}$.

El problema que, al menos, se plantea en las siguientes páginas se basa exactamente en esa oposición equipolente de dos familias, una frente a otra, con una dificultad añadida: no se ha llegado a un consenso en la actualidad ni siquiera sobre la lengua en que fue escrito el original.

\section{La lengua Originaria de los HECHOS DE TOMÁS (HT)}

Este es el caso de los HT, que parecen haberse conservado íntegros con excepción del "Himno de la Perla" ( $\mathrm{HPrl}$ ) en dos versiones, siria y griega, transmitidas por un nutrido grupo de manuscritos. En cuanto a las ediciones realizadas a partir de los testimonios en lengua siríaca, en la que tradicionalmente se considera que fue escrito el original, consta como

9 Alberto Bernabé, op. cit., p. 55, n. 17.

10 Alberto Bernabé, ibidem, p. 56 y n. 20. 
primera la de Wright $(1871)^{11}$, seguida por la más reciente de Burkitt y Smith Lewis (1900) ${ }^{12}$, quienes además tomaron en consideración los nuevos hallazgos codicológicos ${ }^{13}$.

Por su parte, la versión griega ha merecido las ediciones de C. Thilo $(1823)^{14}$, la más actual de Lipsius-Bonnet $(1903)^{15}$ y la incluida en la importante monografía de Klijn $(1962)^{16}$. En estas dos últimas, los autores toman en consideración un número muy superior de manuscritos, pues de los cuatro de Thilo se pasa a los veintiuno de Bonnet y se añade, además, la versión griega de $H \operatorname{Pr}^{17}$. No obstante, excepción hecha de lo referente a la colocación de algunos capítulos en el decurso de la obra, las mejoras sólo incluyen unas pocas variantes de lectura, diferentes respecto a la edición primera de Thilo ${ }^{18}$.

A pesar de estos esfuerzos para conseguir una lectura completa de todos los pasajes incluidos en este corpus, la acribia de los editores no puede ocultar el accidentado carácter de la transmisión textual de estos Hechos. Tanto es así, que, como decíamos, ni siquiera hay seguridad en lo que respecta a la lengua originaria de los $H T^{19}$. La mayoría de los estudiosos pos-

11 William Wright, Apocryphal Acts of the Apostles, Londres, Williams and Norgate, 1871.

12 Francis Crawford Burkitt, "Fragments of the Acts of Judas Thomas from the Sinaitic Palimpsest", en Select Narratives of Holy Women, ed. Agnes Smith Lewis, Londres, C.J. Clay and Sons, 1900, Appendix VII, 23-44.

13 Albertus Frederik Johannes Klijn, The Acts of Thomas. Introduction, Text, Commentary, Leiden, Brill, 2003² (1962).

14 Johann Carl Thilo, Acta S. Thomae Apostoli, Leipzig, Fabrician, 1823.

15 Richard Adelbert Lipsius-Max Bonnet, Acta Apostolorum Apocrypha II.2, Leipzig, Hermann Mendelsohn, $1972^{2}$ (1903).

16 Albertus Frederik Johannes Klijn, op. cit.

17 Susan E. Myers, Spirit Epicleses in the Acts of Thomas, Tübingen, Mohr Siebeck, 2010, pp. 73-74.

18 Así, por ejemplo, tanto Lipsius-Bonnet, como Klijn, de acuerdo con el texto siríaco, sitúan acertadamente el extenso rezo de Tomás tras el capítulo 144, en lugar de la colocación griega, ubicada durante el martirio del apóstol, capítulo 167.

19 Se conocen unos ochenta manuscritos que recogen parcial o de manera completa $H T$, entre los que destancan el ms. U del s. XI, conservado en el Vaticano, y P, en la Biblioteca Nacional de París, que conserva HPrl; Max Bonnet, Acta Thomae. Supplementum Codicis Apocryphi, 1, Leipzig, Hermann Mendelssohn, 1883, pp. VII-X; Hans-Josef Klauck, The Apocryphal Acts of the Apostles. An Introduction, 
tulan que la obra sería fruto de un viaje de ida y vuelta de la lengua siria a la helena: debió de existir un original 'fantasma' - por no conservado- en siríaco, que, poco después, habría sido vertido al griego — momento en el que sus páginas fueron profundamente modificadas bajo el tamiz del incipiente cristianismo ortodoxo ${ }^{20}$ —, para, finalmente, ser traducido de nuevo de la lengua helena a una segunda versión siríaca, la que conservamos hoy día ${ }^{21}$.

¿Cuál es la base sobre la que se asienta la hipótesis de un original sirio? En primer lugar, el origen de la discusión remonta a un artículo y a una nota científica a cargo de F. C. Burkitt ${ }^{22}$, a partir de la edición de W. Wright $^{23}$, en los cuales el investigador se hacía eco de ciertas desviaciones, sirianismos, topónimos y antropónimos que, en su opinión, llevaban a la conclusión de que el texto griego fuera una traducción de una versión siria no conservada ${ }^{24}$.

Waco, Baylor University Press, 2008, pp. 141-142.

20 Hans-Josef Klauck, op. cit., p. 142.

21 Sobre el "Himno de la Perla" en concreto, Susan E. Myers, op. cit., p. 74, n. 52; Lautaro Roig Lanzillotta, "A Syriac Original for the Acts of Thomas? The Hypothesis of Syriac Priority Revisited", en Early Christian and Jewish Narrative. The Role of Religion in Sharping Narrative Forms, eds. Ilaria Ramelli \& Judith Perkins, Tubinga, Mohr Siebeck, 2015, p. 105 y n. 1. Acerca del resto de versiones en otras lenguas de ATh, cf. Maurice Geerard, Clavis Apocryphorum Novi Testamenti, Turnhout, Brepols Publishers, 1992, pp. 147-152; Hans-Josef Klauck, op. cit., p. 142. La aceptación más reciente de esta teoría que conocemos, siguiendo los postulados de Klijn, se encuentra en Dylan M. Burns, "The Garment Poured Its Entire Self Over Me”, en Gnosticism, Platonism and the Late Ancient World, ed. Kevin Corrigan and Thomas Rasimus, Leiden-Boston, Brill, 2013, p. 268.

22 Francis Crawford Burkitt, "The Original Language of the Acts of Judas Thomas", Journal of Theological Studies, I (1900) 280-290; "Another Indication of the Syriac Origin of the Acts of Thomas", Id. II (1901) 94-95. Más reciente es el trabajo de Harold W. Attridge, "The Original Language of the Acts of Thomas", en Of Scribes and Scrolls. Presented to J. Strugnell, ed. Harold W. Attridge, J.J. Collins y T.H. Tobin, Lanham-New York-London, University Press of America-CTS, 1990, pp. 241-250. Véase, además, Max Bonnet, op. cit., pp. XX-XXII.

23 Lautaro Roig Lanzillotta, op. cit., pp. 107-108.

24 Sirvan de ilustración las adiciones o desviaciones respecto del texto griego en HT 5

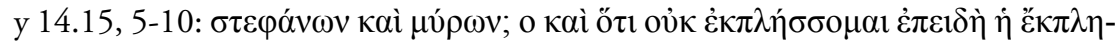

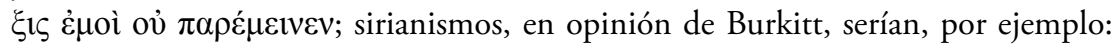

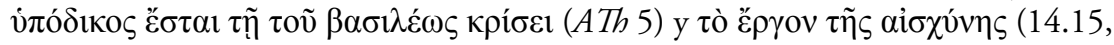


Una segunda razón que ha servido para apoyar la hipótesis del original sirio ha sido defendida más recientemente por Marcovich ${ }^{25}$. Esta se refiere a la existencia en ciertos pasajes de la versión helena de los HT de lo que él llama 'Doppeldreier', esto es, un dístico con tres golpes rítmicos en cada verso. Así, en su opinión, esta versificación típicamente siríaca o aramea habría sido tenida en cuenta por el traductor griego, quien habría intentado mantenerla, según queda propuesto por Marcovich, al menos en el conocido como "Himno de la novia"26.

Esta vía interpretativa caló en los investigadores posteriores, quienes no sólo la aceptaron, sino que la enriquecieron con nuevos argumentos, mediante una lectura que confiaba con rotundidad en la existencia del texto sirio no conservado y por ello anterior al griego. Así Klijn, en su traducción y comentario de $H T$, escribe ${ }^{27}$ :

The choice of this text was made because it is now generally assumed that these Acts were originally written in Syriac and secondly because the text mentioned above is the oldest integral Syriac text of this writing.

No obstante, Klijn pronto — dos páginas después— advierte que: "It is,

0-5). Véase Francis Crawford Burkitt, op. cit., pp. 283-284. Contra Lautaro Roig Lanzillotta, op. cit., pp. 111-120; sobre antropónimos y topónimos, 120-122 .

25 Véase Miroslav Marcovich, "The Wedding Hymn of Acta Thomae", en Id., Studies in Graeco-Roman Religions and Gnosticism, v. IV, Leiden, Brill, 1988, pp. 156-157, n. 2.

26 Contra Lautaro Roig Lanzillotta, op. cit., pp. 108-111.

27 Cf. Albertus Frederik Johannes Klijn, op. cit., p. 1. Así, además de los sirianismos de Burkitt, Klijn añade tres argumentos más: a) El texto sirio es más largo que el griego, como se observa especialmente en los capítulos 13, 33, 34, 59 y 70; b) La existencia de una cierta preferencia por describir el bautismo oriental en el texto sirio - esencialmente que éste tendrá lugar en agua corriente, en un río- frente al occidental, que predominaría en el griego - aunque ya el autor advierte que en ciertos pasajes esta tendencia no se cumple-; c) Ciertas omisiones del texto griego respecto del sirio o adaptaciones al cristianismo ortodoxo; véase Albertus Frederik Johannes Klijn, op. cit., pp. 8-14. También, a este respecto, véase H. Jan Willem Drijvers, "The Acts of Thomas", en New Testament Apocrypha II, ed. Wilhelm Schneemelcher y R. Mcl. Wilson, Cambridge-Louisville, AUSS, 1992, p. 323; Antonio Piñero, Los Hechos Apócrifos de los Apóstoles, vol. II, Madrid, BAC, 2005, pp. 868-869. 
however, too easy to assume an original Syriac text which has been translated into Greek. We suppose that the Acts were written in a bilingual environment in which both the Syriac and Greek versions were originated simultaneously" ${ }^{28}$. En definitiva, se debería entender que, a pesar de lo afirmado y argumentado por la tradición, los dos textos, el sirio y el griego, fueron compuestos casi simultáneamente dentro de un contexto bilingüe.

En nuestra opinión, en este enfrentamiento entre dos versiones en distintas lenguas, una frente a la otra, creemos que mantener la hipótesis de que la versión griega procede de una anterior siríaca presenta claros problemas de distinto orden. En cuanto a aquellas de orden eminentemente extrínseco:

- En primer lugar, hay que señalar el género literario y el grupo en el que el texto suele incluirse. Dada la clara relación, a niveles conceptual y literario, entre los cinco Hechos Apócrifos más antiguos, a saber, Hechos de Juan, de Andrés, de Pedro, de Pablo y de Tomás ${ }^{29}$, parecería extraño postular para los cuatro primeros una lengua, la griega, y una fecha composición del todo diversas respecto del quinto.

- Es significativo, en segundo lugar, que dicha relación entre los Hechos Apócrifos fue ya percibida en la antigüedad, pues la tradición suele atribuir la composición de estos cinco a un mismo autor, Lucio Carino $^{30}$. Más allá de la fiabilidad histórica que se otorgue a este dato, parece claro que esta noticia implicaría, al menos, una circulación del texto en griego ya en época temprana, pues, de lo contrario, se haría difícil comprender esta atribución, ficticia o no, de todos los textos a un mismo personaje. Por consiguiente, postular un original en la lengua siria para $H T$, mientras que el resto estuviera escrito en griego, sería, en nuestra opinión, un sinsentido.

28 Albertus Frederik Johannes Klijn, op. cit., p. 3; Hans-Josef Klauck, op. cit., p. 142. También apunta a una creación en un área siria bilingüe Susan E. Myers, op. cit., 36, aunque mantiene la hipótesis de una 'rápida traducción'.

29 Lautaro Roig Lanzillotta, op. cit., p. 106 y n. 4, 127; Jan N. Bremmer, "The Acts of Thomas: Place, Date and Women", en The Apocryphal Acts of Thomas, ed. Id., Leuven, Peeters, 2001, p. 78.

30 Cf. Phot., Bibl. 114; H. Jan Willem Drijvers, op. cit., p. 323; Knut Schäferdiek, "The Manichean Collection of Apocryphal Acts Ascribed to Leucius Charinus", NTA 2 (1992) 87-100; Lautaro Roig Lanzillotta, op. cit., p. 106 y n. 4. 
- En tercer lugar, la cronología parece oponer también un claro obstáculo a la hipótesis siríaca. Orígenes $(† 254)$ conoció $H T$, pues, según Eusebio, aquél se refirió al apócrifo en su Comentario al Génesis ${ }^{31}$. En tal coyuntura, suponer un original siríaco previo crea importantes problemas. Si, como se afirma, el texto fue escrito a principios del $s$. III —incluso se ha precisado su datación en torno al $230-240^{32}$ - y éste fue conocido por Orígenes en lengua griega, suponemos, habría que postular no sólo un original siríaco anterior a estos años, sino además, una rápida traducción al griego y difusión de la misma en el corto período de una o dos décadas.

Por tanto, coincidimos con la reciente publicación de L. Roig Lanzillotta, donde se refutan los tres principales argumentos intrínsecos que sustentan la propuesta del arquetipo siríaco 'fantasma' — topónimos, antropónimos y Doppeldreier-, aceptando que ${ }^{33}$, si bien es factible que ambos textos fueran escritos en sendas lenguas durante un período y una zona bilingüe comunes - lo que explicaría el uso de términos sirios e incluso la utilización de ritmos arameos o sirios_- la posibilidad de que el texto griego sea una traducción ${ }^{34}$ directa del siríaco resulta del todo improbable.

\section{Conclusiones}

Sin duda es imprescindible la búsqueda de esa exactitud científica a la que nos referíamos al principio, aunque ante una oposición como la actual, en los límites de la estemática maasiana, resulta imprescindible tomar en cuenta elementos extrínsecos al texto para deducir, al menos, la lengua originaria del texto. Es nuestra intención en próximas publicaciones abordar la imprescindible y necesaria edición de los HT sin partir de los apriorismos aceptados hasta el momento.

31 Eus., $H E$ 3.1; sobre el comentario de Orígenes al Génesis.

32 Jan N. Bremmer, op. cit., p. 77. También, Susan E. Myers, op. cit., pp. 44-56, concluye que habría un primer escritor, a mediados del s. II, y un redactor que reunió todo el material en Nisibis a mediados ya del s. III, p. 56.

33 Lautaro Roig Lanzillotta, op. cit., p. 122.

34 Véase, a este respecto, Bentley Layton, The Gnostic Scriptures. A New Translation with Annotations and Introductions, New York, Bantam Doubleday, 1987, p. 361. 
Asimismo, esta propuesta reconfigura por completo el significado literario que hasta ahora se atribuía a los HT al completo y al HPrl en particular, dado que, una vez puesta en duda la existencia de ese original siríaco 'fantasma', las fuentes de inspiración generalmente aceptadas - tendentes a encontrar en sus líneas trazas de corrientes de pensamiento orientales como los de $\mathrm{Mani}^{35}$, Bardesanes ${ }^{36}$ y Taciano ${ }^{37}$ —, deberán ser también reevaluadas.

35 Véase H. Jan Willem Drijvers, op. cit., 337-338; W. Bousset, Hauptprobleme der Gnosis, en Forschungen zur Religion und Literatur des Alten und Neuen Testaments, 10 (1907) pp. 276-319; Guenther Bornkamm, Mythos und Legende in den apokryphen Thomas-Akten: Beiträge zur Geschichte der Gnosis und zur Vorgeschichte der Manichäismus, Göttingen, Vandenhoeck \& Ruprecht, 1933, pp. 115-117. No obstante, Hans-Josef Klauck, op. cit., pp. 148-149, arroja algo de luz a este respecto, al confirmar que evidentemente la cronología hace imposible una influencia maniquea en $H T$, especialmente en aquellos textos que podemos considerar más antiguos, como $\mathrm{HPrl}$ - texto en el que se centran los argumentos para defender una influencia maniquea.

36 Véase H. Jan Willem Drijvers, Bardaisan of Edessa, Assen, Van Gorcum and Co., 1966, y su más reciente "The Acts of Thomas", op. cit., pp. 322-338. También Jan N. Bremmer, op. cit., pp. 74, 77; L.P. van Den Bosch, "India and the Apostolate of Thomas", en Jan N. Bremmer, op. cit., p. 136 (125-148); Hans-Josef Klauck, Jan N. Bremmer, op. cit., p. 146. En nuestra opinión, los argumentos de orden cosmológico, teológico y ético que se aducen presentan serias contradicciones, siendo la más importante, quizá, la supuesta influencia encratita, a la que recientemente se ha opuesto también Susan E. Myers, op. cit., pp. 36-37 y n. 38.

37 Lautaro Roig Lanzillotta, op. cit., p. 107; Erik Peterson, "Einige Bemerkungen zum Hamburger Papyrus-Fragment der Acta Pauli”, Vig. Christ. III (1949) 142-162; Albertus Frederik Johannes Klijn, op. cit., p. 161 y n. 22; Hans-Josef Klauck, op. cit., pp. 177-179. Contra H. Jan Willem Drijvers, op. cit., pp. 335-336. Un elemento clave que, sin embargo, separa ambas tradiciones es, en nuestra opinión, lo referido a la concepción del alma humana. Ésta última, según Taciano, fallece junto con el cuerpo y no llegará a trascender hasta el fin de los días, lo que se aleja de la vision antropológica que ofrecen $H T$ y HPrl, en especial; Tat., Orat. 13.1 y 6.1-2. 